\title{
Life-threatening Events in Respiratory Medicine: Misconnections of Invasive and Non-invasive Ventilators and Interfaces*
}

\section{Lebensbedrohliche Zwischenfälle in der Beatmungsmedizin: Fehlkonnektionen von invasiven und nicht-invasiven Beatmungsgeräten}

Authors

Institutions
S. Stieglitz ${ }^{1,2}$, S. George ${ }^{1,2}$, C. Priegnitz ${ }^{1,2}$, L. Hagmeyer ${ }^{1,2}$, W. Randerath ${ }^{1,2}$

${ }^{1}$ Clinic for Pneumology and Allergology, Centre for Sleep and Ventilation Medicine

${ }^{2}$ Bethanien Hospital, Institute of Pneumology, University Witten/Herdecke received 19.11.2012

accepted 12.1.2013

Bibliography

DOI http://dx.doi.org/

10.1055/s-0032-1326230

Published online: 11.3.2013

Pneumologie 2013; 67: 228-232

(c) Georg Thieme Verlag KG

Stuttgart · New York

ISSN 0934-8387

Corresponding author

Dr. med. Sven Stieglitz

Bethanien Krankenhaus Solingen

Aufderhöher Straße 169-175

42699 Solingen

sven.stieglitz@klinik-bethanien.de

\section{Abstract \\ $\nabla$}

Purpose: Both the parallel use of intensive care unit (ICU)-ventilators and ventilators dedicated to non-invasive ventilation (NIV), as well as the construction of some expiratory valves in single circuit breathing tubes may lead to misconnections which are potentially fatal for the patient. Methods: We demonstrate first a case of a misconnected expiratory valve in a patient with invasive home ventilation. In a second case, the mistaken connection of a non-invasive ventilator to an endotracheal tube leading to carbon dioxide $\left(\mathrm{CO}_{2}\right)$-rebreathing is demonstrated. A third case describes a patient with home non-invasive ventilation who had been delivered a non-vented mask out-of-hospital, likewise leading to $\mathrm{CO}_{2}$-rebreathing.

Conclusion: Human error is the main reason for critical incidents in medicine and the most serious unintended events often involve mechanical ventilation. A regular instruction of medical staff and patients is necessary. The demonstrated misconnections are examples of latent errors "waiting to happen". To prevent these errors from being made in the future, technological solutions similar to the aviation effort to improve safety are needed.

\section{Zusammenfassung \\ $\nabla$}

Hintergrund: Die Kompatibilität verschiedener Beatmungssysteme untereinander ist problematisch und kann zu Zwischenfällen führen. Dies betrifft sowohl die parallele Verwendung von Ventilatoren für invasive wie nicht-invasive Beatmung (NIV) als auch Beatmungszubehör (Tuben, Ausatemventile).

Methode: Anhand von 3 Fallberichten werden Beatmungszwischenfälle durch Kompatibilitätsprobleme demonstriert.

Ergebnisse: In einem ersten Fall berichten wir von einer Patientin mit außerklinischer Beatmung, die sich nach Schlauchdiskonnektion fälschlicherweise an die Ausatemöffnung des Exspirationsventils rekonnektiert hat. Im zweiten Fall führte die fälschliche Konnektion eines NIV-Beatmungsgerätes an einen Endotrachealtubus zur $\mathrm{CO}_{2}-$ Rückatmung. Der dritte Zwischenfall beschreibt einen Fall, bei dem ein Patient mit nicht-invasiver Heimbeatmung versehentlich mit einer Maske ohne Ausatemventil versorgt wurde.

Schlussfolgerungen: Menschliche Fehler sind ein Hauptfaktor für kritische Zwischenfälle in der Medizin und die gravierendsten Ereignisse betreffen die Beatmungsmedizin. Bei den hier gezeigten Möglichkeiten zur Fehlkonnektion besteht konstruktionsbedingt stets die Gefahr, dass die Fehler auftreten. Neben intensiver Schulung von Patienten, Angehörigen und medizinischem Personal halten wir auch technische Lösungen für erforderlich.

\section{Objective}

$\nabla$

More than a million patients admitted to critical care beds within the United States receive mechanical ventilation annually, usually for just a few days [1]. It is expected, that the incidence of mechanical ventilation projected to the year 2026 will increase by about $80 \%$ due to aging baby boo- mers [2]. A lot of patients undergo intubation and invasive ventilation but we have learned, that the application of non-invasive ventilation (NIV) may significantly improve the outcomes of selected

\footnotetext{
* Contents of this article have been reported in part at the annual meeting of the German respiratory society April 2011 in Dresden.
} 
patients with respiratory failure, decreasing the need for endotracheal intubation and reducing mortality [3]. In an European survey of 2008 [4] NIV utilisation at ICU was estimated to be 53 $\%$ among pulmonologists and 34\% among intensivists/anesthesiologists, with the oro-nasal mask being the most frequently used interface.

In recent years, an increasing number of patients have been registered using home mechanical ventilation (HMV). The prevalance of HMV was estimated to be $6.6 / 100,000$ in the 16 European countries surveyed in the Eurovent Study in 2002 [5]. The underlying diseases in the 21,526 represented HMV users were chronic obstructive pulmonary disease (COPD), restrictive disorders and neuromuscular disorders. HMV became feasible due to advances in technology enabling the production of safe and mobile ventilators [6].

For ventilatory support, dedicated ventilators for acute NIV and ICU-ventilators with NIV settings were used with almost equal distribution rates, although NIV-ventilators tend to have some technical limitations [7]. Various ventilators for invasive and non-invasive ventilation have been developed, some of which are suitable for both, ventilation via an endotracheal tube or non-invasive ventilation via mask.

Characteristic of bilevel devices designed for NIV is the application of a single circuit ventilation system. The advantage of single circuits is their lower weight compared to double circuit systems of ICU-ventilators and a simpler handling, which is particularly important for the out-of-hospital care of ventilated patients. Invasive ventilation with a single circuit ventilation system requires an expiration valve. In most cases, this expiration valve is located within the tubing circuit of the ventilator. The use of both, ICU-ventilators and NIV-ventilators as well as the use of ventilators capable of delivering invasive and non-invasive ventilation within one ICU or weaning unit, can provoke application errors by mixing up these different tubing respective valve systems, particulary if concepts of the applied ventilator and tubing systems are not understood by caregivers. Furthermore, the expiratory valves of some single-circuit breathing tubes carry a risk for faulty usage. In this instance patients can put themselves at risk when reconnection to the ventilator is being performed without help of a caregiver, especially at night. A spectrum of potential errors is demonstrated by the following three cases.

\section{Material and methods: \\ $\nabla$}

\section{Case 1}

Case 1 involves a 67-year-old female nursing home resident under treatment with home invasive mechanical ventilation for COPD. The patient had been ventilated for 24 hours per day by a home care ventilator (VS Integra, Resmed Ltd, NSW, Australia) with an inspiratory pressure of $30 \mathrm{mbar}$, an expiratory pressure of $5 \mathrm{mbar}$ and a respiratory rate of $20 / \mathrm{min}$ (assisted pressure controlled ventilation).

The patient mobilized herself independently from bed to chair, which lead to the disconnection from the extension tube. Disconnection from the breathing tube is a common phenomenon which can occur frequently. The patient had been ventilated long-term and was experienced, so she did not call for help. Nevertheless, she made the mistake of reconnecting the extension tube, not to the breathing tube, but to the expiratory valve ( $\bullet$ Fig. 1). Consequently, the patient was no longer ventilated. The nurses were alerted by the alarm of the ventilator, however
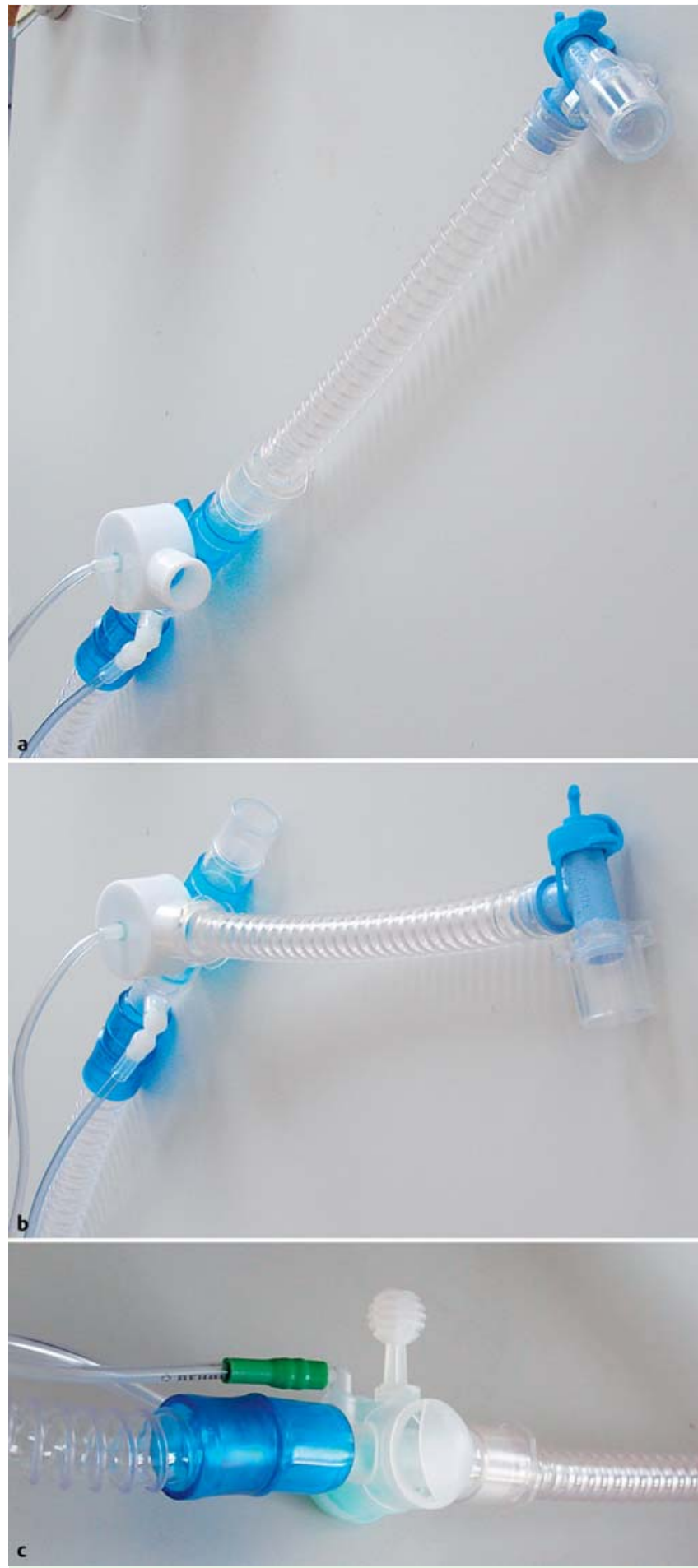

Fig. 1 a Breathing tube with active expiration valve (white) and extension tube. $\mathbf{b}$ Misconnection by combining the extension tube directly to the expiration valve, thereby interrupting the ventilation. $\mathrm{c} A$ technical solution preventing misconnection of the breathing tube.

on arrival the patient was already unconscious and pulseless. After correct reconnection of the breathing tube and a brief period of resuscitation, the patient was successfully revived.

\section{Case 2}

A second critical incident was caused by the possible connection of a ventilator for non-invasive ventilation to an endotracheal tube at a weaning unit. A 65-year-old patient underwent a pneu- 


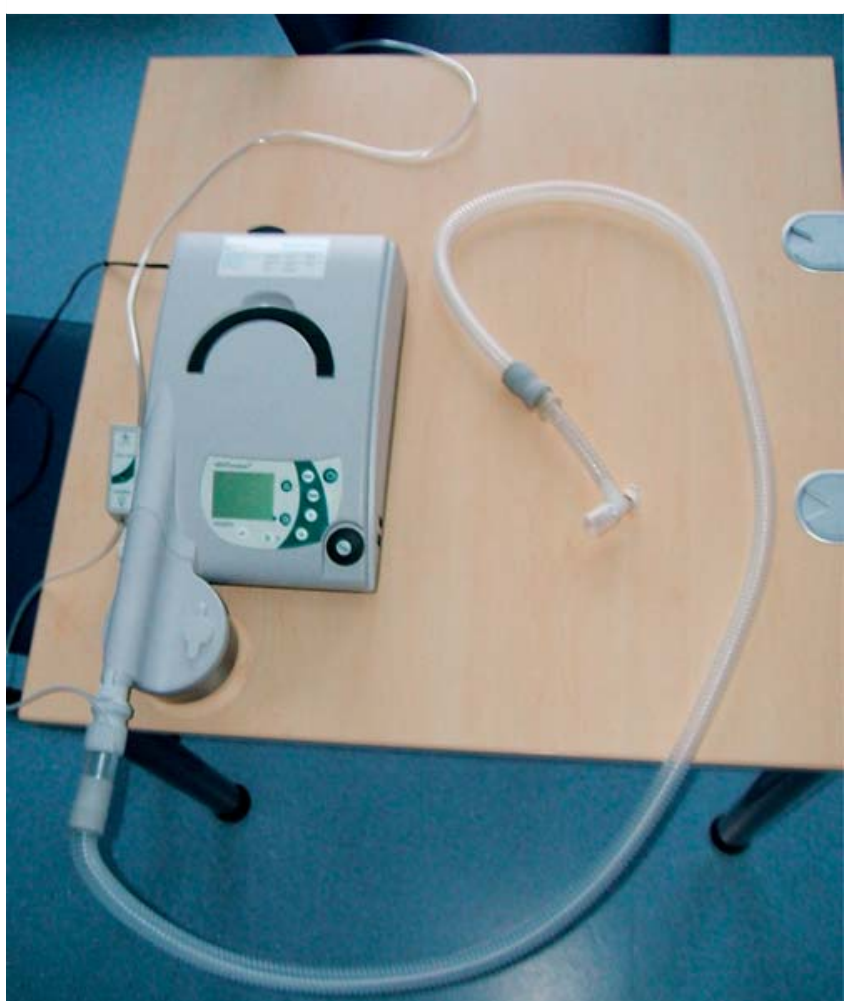

Fig.2 Misconnection of a ventilator designed for non-invasive ventilation to the extension of an endotracheal tube. The ventilator tube has no expiration valve, so that rebreathing of $\mathrm{CO}_{2}$ occurs.

monectomy following a diagnosis of lung cancer. The patient was long-term ventilated following post-operative complications and was transferred to our weaning centre. After 30 days of ventilation, decannulation was possible. Because of the prolonged period of invasive ventilation, non-invasive ventilation (Ventimotion, Weinmann Inc., Hamburg, Germany) was immediately initiated, although the carbon dioxide $\left(\mathrm{CO}_{2}\right)$ was not elevated. Due to a respiratory infection, the condition of the patient deteriorated over the following 5 days, so that invasive ventilation and re-tracheotomy became necessary. The invasive ventilation was inadvertently performed with the bilevel ventilator, which is only approved for non-invasive ventilation. This ventilator device operates with a single circuit system and a so called leaky valve instead of an expiration valve. This can lead to severe rebreathing of the expired gas when connected directly to an endotracheal tube without the use of a leaky valve. Fig. 2 demonstrates how easily this faulty connection can be performed. Ventilation in this way, with an oxygen $\left(\mathrm{O}_{2}\right)$ supply of $4 \mathrm{l} / \mathrm{min}$ without the elimination of $\mathrm{CO}_{2}$ led to excellent oxygen delivery (partial pressure of oxygen $\left(\mathrm{pO}_{2}\right) 253$ torr $(33.73 \mathrm{kPa}), \mathrm{O}_{2}$ saturation $100 \%$ ) but an immediate marked increase of partial pressure of carbon dioxide $\left(\mathrm{pCO}_{2}\right)$ to 104 torr $(13.87 \mathrm{kPa})(\mathrm{pH} 6.9)$ and 40 minutes later to 165 torr $(22 \mathrm{kPa}$ ) ( $\mathrm{pH} \mathrm{6.8)}$. Additionally, a severe metabolic acidosis developed ( $\mathrm{BE}-19.8)$. The appearance of a metabolic acidosis is characteristic of severe hypercapnea as previously documented in apnea ventilation [8-9]. Upon realisation of the misconnection and exchange to an appropriate invasive ventilator (VS Integra, ResMed Ltd, NSW, Australia), normocapnea was quickly restored. Despite the pronounced hypercapnea, no adverse events were evident and the patient was subsequently successfully weaned from the ventilator.

\section{Case 3}

The danger of compatibility between non-invasive ventilatortubing systems and endotracheal tubes extends further to the connectivity of non-invasive ventilators with non-vented masks (masks without a leaky valve). The third case involves a patient receiving nocturnal non-invasive ventilation for more than three years due to chronic ventilatory failure as a consequence of chronic obstructive pulmonary disease. A new mask was ordered and delivered to the patient's home. A non-vented mask was mistakenly delivered, leading to rebreathing and hypercapnea resulting in a respiratory emergency. Blood gas analysis upon hospital admission showed a $\mathrm{pCO}_{2}$ of $104 \operatorname{torr}(13.87 \mathrm{kPa})$ with a markedly elevated $\mathrm{pO}_{2}$ - the typical constellation seen in cases of rebreathing of oxygen enriched air. Fig. 3 demonstrates the possibility of connecting a ventilator system which requires a leaky valve in the tubing system or as part of the mask, directly to a non-vented mask, facilitated by the use of an adapter. As mentioned, this results in $\mathrm{CO}_{2}$ rebreathing. In addition, the connection of a breathing tube with an expiratory valve to a vented mask can result in greater leakage and therefore insufficient ventilation.

\section{Discussion}

We present a case series of serious incidents in different situations of ventilator medicine that lead to near fatal incidents. In the last few years there have been an increasing number of publications addressed to the field of medical errors and incidents [10].

Health care quality problems are classified into 3 categories: underuse (failure to provide a necessary health care service), overuse (e.g. prescribing antibiotics for viral infections) and misuse. The demonstrated cases represent misuse problems which could have been preventable [11]. Most of the errors are latent errors, "waiting to happen", arising from poorly designed processes, systems of care or, like in our examples, the result of technical systems which do not have the safeguards to prevent such incidents from occurring.

The likelihood of an incident that will injure a patient has been examined in the past and was at least $3.7 \%$ of all hospitalizations. Nearly $30 \%$ of these adverse advents were due to negligence. Negligence was associated with more severe adverse effects. In total $50 \%$ of the deaths due to adverse events were caused by negligence [12]. In summary about 100.000 patients are estimated to die as a consequence of preventable incidents annually in hospitals in the United States, with many more incurring injuries. Under-reporting of adverse events is estimated to range from $50-96 \%$. The frequency of medical accidents exceeds the combined number of deaths and injuries from motor vehicles, air crashes, suicides, falls, poisonings, and drownings [13]. In fact human errors contribute from $63 \%$ [14] to $80 \%$ of critical incidents in medicine [15]. In one study human errors prolonged ICU stay by 425 patient-days, amounting to $15 \%$ of ICU time [16]. Further studies have identified unintended events mainly involving airway management, mechanical ventilation [17] and equipment [18].

In the following discussion, we would like to make some proposals for solutions that prevent incidents and serve to increase the safety of ventilated patients. 


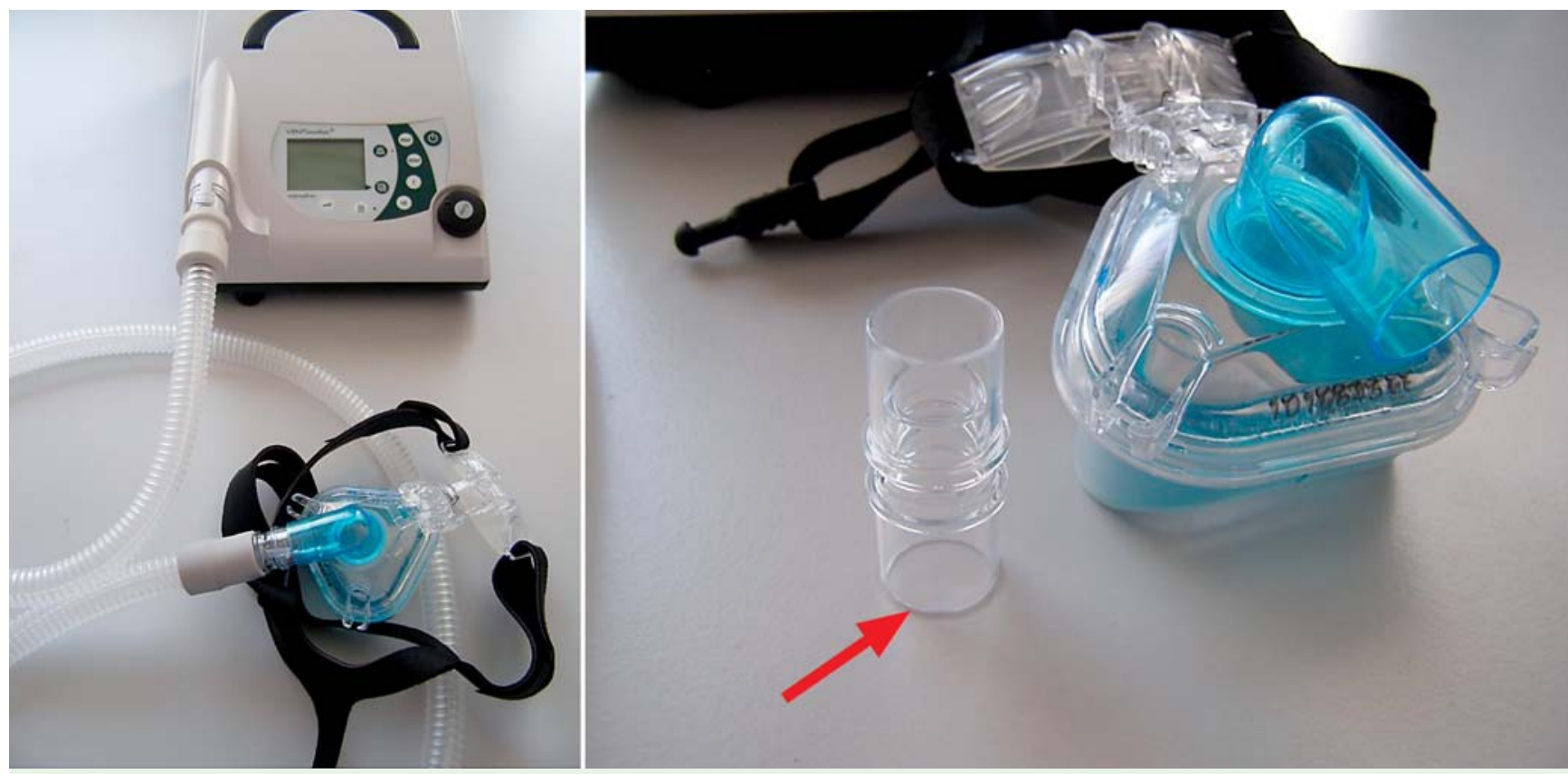

Fig. 3 This picture demonstrates a non-invasive ventilation system which requires a vented mask (with expiration valve). The ventilator has been connected to a non-vented nasal mask (blue articulation piece) (left). An adaptor is needed (red arrow) as the manufacturer of the ventilator inhibits misconnections without the use of additional connecting devices (right).

In the first case the near fatal incident was provoked by the ability to misconnect the breathing tube, although there is no technical need for the breathing tube to be compatible with the expiratory valve. One has to expect, that patients or relatives may try to reconnect breathing tubes following disconnection and that there is a chance to make mistakes. For this reason, extra precaution must be taken to ensure that the expiration valve in a single tube system is incorporated into the circuit in a way that makes such a misconnection impossible.

The second case demonstrates a critical incident caused by the compatibility between circuit systems used for non-invasive ventilation with those used for invasive ventilation. Invasive ventilation of patients with a pure non-invasive ventilator leads to excessive $\mathrm{CO}_{2}$-retention by means of rebreathing. Enquiries to other hospitals and home care providers suggest that similar incidents involving this connectivity of invasive and non-invasive-ventilatory devices have taken place, although official data are missing. The first lesson that could be learned from the second case is that the simultaneous use of ventilators for invasive ventilation and those for non-invasive ventilation may lead to a dangerous mixup. In this regard, the use of ventilators that are able to offer both invasive and non-invasive modes might complicate the situation further. Therefore we recommend a clear separation between invasive and non-invasive ventilators. For this reason in our centre, we use ventilators that are approved for both modes exlusively for invasive or non-invasive ventilation. Technical solutions are needed in order to avoid misconnections from occurring.

The second lesson that can be learned is that even marked hypercapnia could only be detected by measuring $\mathrm{CO}_{2}$. The oxygen saturation in our case remained high, thus being an inappropriate instrument to detect hypercapnia when additional oxygen is administered. There are three essential techniques to measure $\mathrm{CO}_{2}$ and therefore the effect of ventilation: by blood gas analysis, by end-tidal $\mathrm{CO}_{2}$ concentration or by transcutaneous measurement [19]. Therefore we recommend routine measurement of $\mathrm{CO}_{2}$ not only inside the ICU but also in the home care setting of ventilated patients, using a method appropriate to the given setting.

The third case demonstrates an inappropriate connection of vented and non-vented masks to ventilators. Some manufacturers design the connection between the mask and tubing ('the elbow piece') of vented and non-vented masks in different colours (e.g. lucent and blue) to avoid the potential mix-up of vented and non-vented systems. However, as this elbow piece fits to both types of masks, the error still has the potential to occur, especially after removing this piece to clean the mask.

The example demonstrates that small changes in the HMV equipment may have serious effects on the outcome of a patient. A regular check-up especially after replacement of ventilator equipment, such as a mask, is recommended.

One may argue that incorrect use of medical equipment and therefore the human factor rather than technical problems is the main reason for the critical incidents in this case series. Thus it could be believed that improving training of nursing staff, the patient and caregivers in the use of ventilators would simply solve the problem. Indeed, continued training is important. As pointed out above indeed the human factor is the main reason for errors and incidents. Remarkably, misuse of the ventilator equipment in our cases occurred in three different situations and were caused by three different people: the patient herself or himself, the nursing staff and an employee of the home care provider. Due to the variety of possible mistakes and the variety of parties involved in the handling of ventilators and ventilator equipment every technical solution to prevent such incidents is of great importance. Manufacturers should be encouraged to develop safeguards to improve the safety of mechanical ventilation. This suggests that a technological solution to reduce human errors in mechanical ventilation has to be the use of "engineered safety devices" that physically prevent errors from being made. One classic example is the system of gas connectors that prevent a gas hose or cylinder from being installed at the wrong site [20]. 


\section{Summary}

In summary, we present a series of critical incidents in ventilator medicine, all caused by the misconnection of ventilators or masks. The increasing use of NIV-ventilators within the ICU and in the homecare setting make incidents caused by operating errors more likely. A regular instruction of medical staff and patients including their families is needed.

The described scenarios could have been avoided by technical solutions making missconnections impossible to occur. Technical safeguards can prevent human error and thus manufacturers and providers of ventilators and ventilation equipment are encouraged to develop safer systems.

Furthermore, as demonstrated, the measurement of $\mathrm{CO}_{2}$ is of great importance in the diagnosis of hypoventilation and should therefore also be considered in selected patients with $\mathrm{HMV}$. This additional measurement of $\mathrm{CO}_{2}$ after replacement of a ventilator mask would increase patient safety in HMV.

\section{Conflicts of interest}

$\nabla$

The authors have no conflicts of interest.

\section{References}

1 Cox CE, Carson SS, Govert JA et al. An economic evaluation of prolonged mechanical ventilation. Crit Care Med 2007; 35: 1918-1927

2 Needham DM, Bronskill SE, Calinawan JR et al. Projected incidence of mechanical ventilation in Ontario to 2026: Preparing for the aging baby boomers. Crit Care Med 2005; 33: 574-579

3 Nava S, Hill N. Non-invasive ventilation in acute respiratory failure. Lancet 2009; 374: 250-259

4 Crimi C, Noto A, Princi P et al. A European survey of noninvasive ventilation practices. Eur Respir J 2010; 36: 362 - 369
5 Lloyd-Owen SJ, Donaldson GC, Ambrosino $N$ et al. Patterns of home mechanical ventilation use in Europe: results from the Eurovent survey. Eur Respir J 2005; 25: 1025-1031

6 Srinivasan S, Doty SM, White TR et al. Frequency, causes, and outcome of home ventilator failure. Chest 1998; 114: 1363-1367

7 Farre $R$, Navajas D, Prats E et al. Performance of mechanical ventilators at the patient's home: a multicentre quality control study. Thorax 2006; 61: 400-404

8 Holaday DA, Ma D, Papper EM. The immediate effects of respiratory depression on acid-base balance in anesthetized man. J Clin Invest 1957; 36: 1121 - 1129

9 Frumin MJ, Epstein RM, Cohen G. Apneic oxygenation in man. Anesthesiology 1959; 20: 789-798

10 Reinertsen JL. Let's talk about error. BMJ 2000; 320: 730

11 Chassin MR, Galvin RW. The urgent need to improve health care quality. Institute of Medicine National Roundtable on Health Care Quality. JAMA 1998; 280: 1000 - 1005

12 Brennan TA, Leape $L L$, Laird NM et al. Incidence of adverse events and negligence in hospitalized patients. Results of the Harvard Medical Practice Study I. N Engl J Med 1991; 324: 370 - 376

13 Barach P, Small SD. Reporting and preventing medical mishaps: lessons from non-medical near miss reporting systems. BMJ 2000; 320: 759 763

14 Frey B, Kehrer B, Losa $M$ et al. Comprehensive critical incident monitoring in a neonatal-pediatric intensive care unit: experience with the system approach. Intensive Care Med 2000; 26: 69-74

15 Wright D, Mackenzie SJ, Buchan I et al. Critical incidents in the intensive therapy unit. Lancet 1991; 338: 676-678

16 Bracco D, Favre JB, Bissonnette $B$ et al. Human errors in a multidisciplinary intensive care unit: a 1-year prospective study. Intensive Care Med 2001; 27: 137-145

17 Capuzzo M, Nawfal I, Campi M et al. Reporting of unintended events in an intensive care unit: comparison between staff and observer. BMC Emerg Med 2005; 5: 3

18 Welters ID, Gibson J, Mogk M et al. Major sources of critical incidents in intensive care. Crit Care 2011; 15: R232

19 Randerath WJ, Stieglitz S, Galetke W et al. Evaluation of a system for transcutaneous long-term capnometry. Respiration 2010; 80: 139145

$20 \mathrm{Gaba}$ DM. Anaesthesiology as a model for patient safety in health care. BMJ 2000; 320: 785 - 788 